\title{
Efeito de fungicidas ao fungo entomopatogênico Metarhizium rileyi
}

\author{
Effect of fungicides on the entomopathogenic fungus Metarhizium rileyi \\ Efecto de los fungicidas sobre el hongo entomopatógeno Metarhizium rileyi
}

Recebido: 10/05/2021 | Revisado: 16/05/2021 | Aceito: 20/05/2021 | Publicado: 07/06/2021

Luis Gustavo Amorim Pessoa

ORCID: https://orcid.org/0000-0003-4646-062X

Universidade Federal de Mato Grosso do Sul, Brasil E-mail: luis.pessoa@ufms.br

Elisângela de Souza Loureiro

ORCID: https://orcid.org/0000-0002-9708-3775

Universidade Federal de Mato Grosso do Sul, Brasil E-mail: elisangela.loureiro@ufms.br

Lidiane Arissa Yokota

ORCID: https://orcid.org/0000-0001-5478-9930

Universidade Federal de Mato Grosso do Sul, Brasil E-mail: lidiane.yokota@ufms.br

Cristina Martins Domingos Rocha

ORCID: https://orcid.org/0000-0002-3891-7143

Universidade Federal de Mato Grosso do Sul, Brasil

E-mail: cristinamartinsrocha09@gmail.com

Ana Carolina Sales

ORCID: https://orcid.org/0000-0001-6690-2048

Universidade Federal de Mato Grosso do Sul, Brasil

E-mail: carolinasagro@gmail.com

Bruno Mateus Ribeiro Dias

ORCID: https://orcid.org/0000-0001-5315-8184

Universidade Federal de Mato Grosso do Sul, Brasil

E-mail: brunomateusagro@gmail.com

Antonio Amorim Pereira Filho

ORCID: https://orcid.org/0000-0002-0277-7345

Universidade Federal de Mato Grosso do Sul, Brasil

E-mail: antonioafilho@live.com

\begin{abstract}
Resumo
O fungo entomopatogênico Metarhizium rileyi é conhecido como agente de controle biológico de vários lepidópteros entre eles destaca-se a família Noctuidae. O objetivo deste trabalho foi avaliar o efeito dos fungicidas sobre o desenvolvimento de dois isolados de $M$. rileyi em condições de laboratório. Foi estudado o efeito in vitro de cinco fungicidas sobre os isolados UFMS 06 e UFMS 07 do fungo M. rileyi. Os produtos foram colocados em placas de Petri contendo o meio de cultura Batata-Dextrose-Ágar (BDA), nas concentrações recomendadas para a aplicação do produto em campo. Após ter incubado o fungo no meio de cultura as placas foram vedadas com filme de PVC e colocadas em câmara climatizada (tipo B.O.D.) a $25 \pm 1{ }^{\circ} \mathrm{C}$, umidade relativa de $70 \pm 10 \%$ e fotoperíodo de 12 horas por um período de 7 dias, foram avaliados o crescimento micelial e concentração de esporos. Para quantificar a porcentagem de germinação foi utilizada uma suspensão de $1,0 \times 10^{6}$ con.mL $\mathrm{m}^{-1}$, sendo mantida em repouso por duas horas nos diferentes fungicidas. Logo após este período foi plaqueado $1,0 \mathrm{~mL}$ da suspensão com o auxílio de uma pipeta graduada $(1 \mathrm{~mL})$ em placas de Petri e espalhada com alça de Drigalsky no meio nutritivo, após a inoculação as placas foram identificadas e vedadas com filme PVC, e incubadas por 20 horas em câmara climatizadas tipo B.O.D. a $25 \pm 1{ }^{\circ} \mathrm{C}$, umidade relativa de $70 \pm 10 \%$ e fotoperíodo de 12 horas. Os fungicidas testados neste trabalho todos eles interferiram no crescimento vegetativo, na produção de conídios e na germinação dos dois isolados do fungo, no teste de índice biológico todos os produtos foram classificados como tóxicos.
\end{abstract}

Palavras-chave: Manejo integrado de pragas; Controle biológico; Fungo entomopatogênico.

\begin{abstract}
The entomopathogenic fungus Metarhizium rileyi is known as a biological control agent for several lepidopterans, among which the Noctuidae family stands out. The objective of this work was to evaluate the effect of fungicides on the development of two isolates of $M$. rileyi under laboratory conditions. The in vitro effect of five fungicides on the UFMS 06 and UFMS 07 isolates of the fungus $M$. rileyi was studied. The products were placed in Petri dishes containing the Potato-Dextrose-Agar (BDA) culture medium, in the concentrations recommended for the application of the product in the field. After incubating the fungus in the culture medium, the plates were sealed
\end{abstract}


with PVC film and placed in an air-conditioned chamber (type BOD) at $25 \pm 1{ }^{\circ} \mathrm{C}$, relative humidity of $70 \pm 10 \%$ and a photoperiod of 12 hours for a period of 7 days, mycelial growth and spore concentration were evaluated. To quantify the germination percentage, a suspension of $1.0 \times 10^{6}$ con. $\mathrm{mL}^{-1}$ was used, being kept at rest for two hours in the different fungicides. Right after this period, $1.0 \mathrm{~mL}$ of the suspension was plated with the aid of a graduated pipette $(1 \mathrm{~mL})$ in Petri dishes and spread with a Drigalsky loop in the nutrient medium, after inoculation the plates were identified and sealed with PVC film, and incubated for 20 hours in an air-conditioned BOD chamber at $25 \pm$ $1{ }^{\circ} \mathrm{C}$, relative humidity of $70 \pm 10 \%$ and photoperiod of 12 hours. The fungicides tested in this work all interfered in the vegetative growth, in the production of conidia and in the germination of the two isolates of the fungus, in the biological index test all products were classified as toxic.

Keywords Integrated pest management; Biological control; Entomopathogenic fungus.

\section{Resumen}

El hongo entomopatógeno Metarhizium rileyi es conocido como agente de control biológico de varios lepidópteros, entre los que destaca la familia Noctuidae. El objetivo de este trabajo fue evaluar el efecto de los fungicidas en el desarrollo de dos aislamientos de $M$. rileyi en condiciones de laboratorio. Se estudió el efecto in vitro de cinco fungicidas sobre los aislados UFMS 06 y UFMS 07 del hongo $M$. rileyi. Los productos se colocaron en placas Petri que contenían el medio de cultivo Papa-Dextrosa-Agar (BDA), en las concentraciones recomendadas para la aplicación del producto en campo. Después de incubar el hongo en el medio de cultivo, las placas se sellaron con film de PVC y se colocaron en una cámara climatizada (tipo DBO) a $25 \pm 1{ }^{\circ} \mathrm{C}$, humedad relativa de $70 \pm 10 \%$ y un fotoperiodo de 12 horas por período de 7 días, se evaluó el crecimiento micelial y la concentración de esporas. Para cuantificar el porcentaje de germinación se utilizó una suspensión de $1.0 \times 10^{6}$ con. $\mathrm{mL}^{-1}$, manteniéndose en reposo durante dos horas en los diferentes fungicidas. Inmediatamente después de este período, se sembró $1.0 \mathrm{~mL}$ de la suspensión con la ayuda de una pipeta graduada $(1 \mathrm{~mL})$ en placas de Petri y se extendió con un asa Drigalsky en el medio nutritivo, luego de la inoculación las placas se identificaron y sellaron con película de PVC, y se incubaron. durante 20 horas en cámara DBO climatizada a $25 \pm 1{ }^{\circ} \mathrm{C}$, humedad relativa de $70 \pm 10 \%$ y fotoperiodo de 12 horas. Los fungicidas probados en este trabajo interfirieron todos en el crecimiento vegetativo, en la producción de conidios y en la germinación de los dos aislados del hongo, en la prueba de índice biológico todos los productos fueron clasificados como tóxicos.

Palabras clave: Manejo integrado de plagas; Control biológico; Hongo entomopatógeno.

\section{Introdução}

O complexo de lagarta presentes na cultura da soja causa desfolha comprometendo o enchimento das vagens, devido à diminuição da área foliar responsável pela fotossíntese, com consequente redução da produção de grãos. Quando se alimentam, removem os tecidos vegetais que contém nutrientes, são polífagas, ocorrendo em diversas culturas de importância econômica (Bueno et al., 2017).

O fungo entomopatogênico Metarhizium rileyi (Ascomycota: Clavicipitaceae) é conhecido como agente de controle biológico de lepidópteros pragas em diversas culturas e é capaz de reduzir drasticamente populações destes insetos (Costa et al., 2015). No Brasil, dentre os hospedeiros suscetíveis a esse agente de controle, destacam-se Spodoptera cosmioides (Walker), Spodoptera frugiperda (J. E. Smith), Helicoverpa armigera (Hübner), Chrysodeixis includens (Walker) (Lepidoptera: Noctuidae) (Dias et al., 2019).

Essas pragas são atacadas pela doença branca causada por $M$. rileyi, que é o mais importante agente de controle natural deste inseto e que ocorre em temperaturas em torno de $25{ }^{\circ} \mathrm{C}$ e umidade relativa do ar acima de $75 \%$. As lagartas são contaminadas pelos esporos do fungo presentes sobre as folhas ou no solo. As lagartas ficam duras e recobertas por bolores brancos, devido ao desenvolvimento externo do micélio, tornando-se verdes com a formação dos esporos (Sujii et al., 2002; Loureiro et al., 2020).

Os produtos químicos a serem utilizados durante o manejo de uma cultura devem ser escolhidos levando-se em consideração a sua classificação toxicológica e seu efeito sobre os inimigos naturais. O impacto da aplicação dos pesticidas sobre os entomopatógenos pode variar em função da espécie e da linhagem do patógeno, da natureza química dos produtos e das concentrações utilizadas (Boiça Junior et al., 2015). Podem atuar inibindo o crescimento vegetativo, a conidiogênese e a esporulação dos microrganismos, e até causando mutações genéticas, as quais podem levar a diminuição da ação à determinada 
praga (Lopes et al., 2018).

Com a aplicação constante de fungicidas para o controle de Phakopsora pachyrhizi tem sido verificado, nos últimos anos, uma redução ou uma inibição da presença do fungo $M$. rileyi. Ainda não há relatos sobre a compatibilidade dos fungicidas que estão sendo usados no controle da doença, com o fungo M. rileyi (Reddy et al., 2018; Barbosa Junior, 2020).

As interações entre os fungos entomopatogênicos e os produtos fitossanitários podem ser positivas, quando ocorre uma ação sinérgica ou aditiva entre o patógeno e o produto, ou negativas, quando ocorre a inibição de um dos componentes, geralmente a do patógeno. Estes produtos, principalmente os fungicidas, inibem, na sua grande maioria, a germinação dos esporos dos fungos diminuindo o potencial de inóculo. Assim, as interações, principalmente as negativas, devem ser consideradas nos programas de Manejo Integrado de Pragas (MIP), pois, quanto mais seletivo e compatível for o produto químico mais eficiente será a conservação do entomopatógeno (Silva et al., 2005). Este aspecto é mais importante em agroecossistemas onde o fungo entomopatogênico é um importante fator para a redução populacional de insetos pragas, sendo considerado um inimigo natural-chave (Khun et al., 2021).

Sendo assim, tornam-se necessário a utilização de produtos seletivos que não afetem o equilíbrio entre as pragas e entomopatógenos. O objetivo deste trabalho foi avaliar o efeito dos fungicidas sobre o desenvolvimento de isolados de $M$. rileyi em condições de laboratório.

\section{Metodologia}

O trabalho realizado seguiu a metodologia de pesquisa laboratorial de natureza quantitativa, segundo proposto por Pereira et al. (2018), utilizando os isolados UFMS 06 e 07 do fungo M. rileyi, multiplicados em placa de Petri contendo meio nutritivo Batata-Dextrose-Ágar (BDA).

O trabalho foi realizado "in vitro", procurando-se avaliar o efeito dos fungicidas sobre os isolados, avaliando-se a germinação dos esporos, crescimento micelial, e a concentração de esporos na presença e ausência dos fungicidas. (Tabela 1). Foi adotado o delineamento experimental inteiramente casualizado com 12 tratamentos (testemunhas e com os fungicidas para cada isolado).

Tabela 1. Tratamentos avaliados no teste de compatibilidade entre os fungicidas e o fungo Metarhizium rileyi.

\begin{tabular}{|c|c|c|c|c|}
\hline Produto comercial & Ingrediente ativo (i.a) & $\begin{array}{c}\text { Grupo } \\
\text { químico* }\end{array}$ & $\begin{array}{c}\text { Doses } \\
\left(\mathrm{L} \mathrm{ha}^{-1}\right)\end{array}$ & $\begin{array}{c}\text { Volume de calda } \\
\left.(\mathrm{L} \mathrm{ha})^{-1}\right)\end{array}$ \\
\hline Aproach Prima SC ${ }^{\circledR}$ & Picoxistrobina $20 \%$ + Ciproconazole $8 \%$ & $\mathrm{E}+\mathrm{T}$ & 0,3 & \\
\hline Domark $100 \mathrm{EC}^{\circledR}$ & Tetraconazole $10 \%$ & $\mathrm{~T}$ & 0,5 & \\
\hline Nativo SC ${ }^{\circledR}$ & Trifloxystrobin $10 \%+$ Tebuconazole $20 \%$ & $\mathrm{E}+\mathrm{T}$ & 0,5 & 200 \\
\hline Gauss $^{\circledR}$ & Epoxiconazole $12,5 \%$ & $\mathrm{~T}$ & 0,3 & \\
\hline Priori Xtra $\mathrm{SC}^{\circledR}$ & Azoxystrobina $20 \%+$ Ciproconazole $8 \%$ & $\mathrm{E}+\mathrm{T}$ & 0,3 & \\
\hline Testemunha & - & - & - & \\
\hline
\end{tabular}

* E - Estrobilurinas T - Triazol

Fonte: Autores (2021).

\subsection{Avaliação do crescimento micelial e concentração de conídios de Metarhizium rileyi}

Para avaliar o crescimento micelial e a concentração de esporos dos isolados, os fungicidas foram adicionados ao 
meio BDA, seguindo as concentrações de cada tratamento, quando o mesmo apresentava temperatura aproximada de $40{ }^{\circ} \mathrm{C}$, evitando assim a degradação dos produtos.

Com o meio ainda não solidificado, a mistura foi vertida em placa de Petri de $9 \mathrm{~cm}$ de diâmetro. Após a solidificação do BDA efetuou-se a inoculação dos isolados por meio de alça de platina em três pontos equidistantes. Após esse procedimento, as placas foram identificadas e vedadas com filme PVC e acondicionadas em câmara de incubação tipo B.O.D. a temperatura de $25 \pm 1^{\circ} \mathrm{C}$, umidade relativa de $70 \pm 10 \%$ e fotoperíodo de $12 \mathrm{~h}$, por um período de sete dias.

Para se avaliar o crescimento micelial do fungo, foi feita medição das colônias, previamente marcadas na parte externa do fundo da placa, em sentidos ortogonais para determinar o diâmetro médio em centímetros logo após os sete dias de incubação.

Foi utilizado o delineamento experimental inteiramente casualizado para fazer a análise de conídios. Foram utilizadas três placas e duas colônias de cada tratamento, e de cada isolado, totalizando 12 tratamentos (testemunhas e com os fungicidas para cada isolado) cada um com 3 placas e contendo 3 colônias por placa totalizando 9 colônias. Dessas, apenas 6 foram aleatoriamente apontadas resultando assim em 6 repetições por tratamento (Pessoa et al., 2020).

Para quantificação da concentração de esporos, as colônias foram recortadas das placas com auxílio de um bisturi cirúrgico estéril e transferidas para tubos de ensaio esterilizados, contendo $10 \mathrm{~mL}$ de água destilada esterilizada + espalhante adesivo (Tween $80^{\circledR}$ ). O mesmo foi agitado manualmente, para a separação dos agregados. Após, realizou-se a contagem de esporos em microscópio com auxílio de uma câmara de Neubauer.

Os dados de crescimento vegetativo e reprodutivo foram transformados para $(x+1)^{0,5}$ e submetidos ao teste de agrupamento de médias de Scott-Knott a $5 \%$ de probabilidade.

\subsection{Porcentagem de germinação dos esporos}

Foi adotado o delineamento experimental inteiramente casualizado com 12 tratamento sendo uma testemunha UFMS 06 e uma testemunha UFMS 07 e 5 tratamentos composto pelos fungicidas para cada isolado, e quatro repetições, e parcelas compostas por 4 placas de Petri.

Para avaliar a porcentagem de germinação dos conídios foi utilizada uma suspensão de $1,0 \times 10^{6}$ con.mL ${ }^{-1}($ Silva et al., 2005), a qual foi feita a raspagem da massa micelial e esporos das colônias de cada isolado cultivado em meio de cultura BDA sem a presença dos fungicidas. Após essa raspagem esses conídios foram transferidos para tubos de ensaio contendo 10 $\mathrm{mL}$ água esterilizada + espalhante adesivo (Tween $80^{\circledR}$ ) e agitado para homogeneização da suspensão, na qual $1 \mathrm{~mL}$ dessa suspensão foi transferido para outro tubo de ensaio contendo $9 \mathrm{~mL}$ de água esterilizada +espalhante adesivo (Tween $80{ }^{\circledR}$ ) juntamente com os fungicidas na dosagem equivalente ao volume de água utilizado, a qual foi mantida em repouso por duas horas. Após este período foi plaqueado $1 \mathrm{~mL}$ da suspensão com auxílio de uma pipeta graduada (1mL), em placa de Petri e espalhada com alça de Drigalsky no meio nutritivo. Após a inoculação, as placas foram identificadas e vedadas com filme PVC, e incubadas por 24 horas em câmara climatizada (tipo BOD) a $25 \pm 1^{\circ} \mathrm{C}$, umidade relativa de $70 \pm 10 \%$ e fotoperíodo de 12 horas.

Após a incubação, foi realizada a contagem de conídios, e contando-se aleatoriamente 100 conídios por placa entre aqueles germinados e não germinados, estabelecendo posteriormente a porcentagem de germinação. Para análise dos dados, foi adotado o padrão do laboratório de controle biológico de instituto Biológico de Campinas: germinação alta 80-100\%, germinação média/alta 60-79\%, germinação média 50-59\%, germinação média/baixa 30-49\% e germinação baixa 0-29\% (Zappelini et al., 2005).

Os dados da germinação dos conídios foram transformados para arcsen $(x / 100)^{0,5}$ e submetidos ao teste de agrupamento de médias de Scott-Knott a $5 \%$ de probabilidade. 


\subsection{Compatibilidade dos diferentes fungicidas com Metarhizium rileyi}

Os dados obtidos também foram submetidos ao cálculo do fator de compatibilidade (IB = índice biológico), proposto por Rossi-Zalaf et al. (2008), que permite a classificação dos produtos em classes de seletividade/compatibilidade, de acordo com o efeito observado em relação aos parâmetros avaliados, sendo calculado pela fórmula:

$\mathrm{IB}=[47(\mathrm{CV})+43(\mathrm{ESP})+10(\mathrm{GER})] / 100$, na qual:

IB = valor corrigido do crescimento vegetativo e reprodutivo para classificação do produto;

$\mathrm{CV}=$ porcentagem de crescimento vegetativo com relação à testemunha;

$\mathrm{ESP}=$ porcentagem de esporulação (conidiogênese) com relação à testemunha;

GER= porcentagem de germinação dos conídios após 24 horas.

Os valores calculados de IB foram comparados com os seguintes limites pré-estabelecidos: 0 a $41=$ tóxico; 42 a $66=$ moderadamente tóxico; > 66 = compatível.

\section{Resultados e Discussão}

\subsection{Crescimento micelial, concentração e germinação de conídios}

Os fungicidas Gauss ${ }^{\circledR}$, Priori Xtra ${ }^{\circledR}$ e Nativo ${ }^{\circledR}$ interferiram no crescimento vegetativo do isolado UFMS 06 sendo nulos em comparação com a testemunha, o mesmo teve um crescimento vegetativo menor comparando com a testemunha, sendo diferente estatisticamente, na presença dos produtos Domark ${ }^{\circledR}$ e Aproach Prima ${ }^{\circledR}$, e todos os fungicidas testados afetaram a concentração de conídios (Tabela 2).

Tabela 2. Crescimento micelial (cm), concentração de esporos e germinação (\%) dos isolados UFMS 06 e UFMS 07 de $M$. rileyi com diferentes fungicidas.

\begin{tabular}{|c|c|c|c|}
\hline Tratamentos & $\begin{array}{c}\text { Crescimento micelial } \\
(\mathbf{c m})^{*}\end{array}$ & $\begin{array}{l}\text { Concentração de } \\
\text { conídios }\left(\times 10^{6}\right)^{*}\end{array}$ & Germinação $(\%)^{* *}$ \\
\hline Testemunha (UFMS 06) & $2,92 \mathrm{a}$ & $2,88 \mathrm{a}$ & $84,50 \mathrm{a}$ \\
\hline Aproach Prima ${ }^{\circledR}$ & $0,39 \mathrm{~b}$ & $0,00 \mathrm{~b}$ & $0,00 \mathrm{c}$ \\
\hline Domark $^{\circledR}$ & $0,34 \mathrm{~b}$ & $0,00 \mathrm{~b}$ & $64,42 \mathrm{~b}$ \\
\hline Nativo $^{\circledR}$ & $0,00 \mathrm{c}$ & $0,00 \mathrm{~b}$ & $0,00 \mathrm{c}$ \\
\hline Gauss $^{\circledR}$ & $0,00 \mathrm{c}$ & $0,00 \mathrm{~b}$ & $0,00 \mathrm{c}$ \\
\hline Priori Xtra ${ }^{\circledR}$ & $0,00 \mathrm{c}$ & $0,00 \mathrm{~b}$ & $0,00 \mathrm{c}$ \\
\hline Testemunha (UFMS 07) & $3,05 \mathrm{a}$ & $4,22 \mathrm{a}$ & $81,53 \mathrm{a}$ \\
\hline Aproach Prima ${ }^{\circledR}$ & $0,48 \mathrm{~b}$ & $0,00 \mathrm{~b}$ & $0,17 \mathrm{c}$ \\
\hline Domark $^{\circledR}$ & $0,00 \mathrm{c}$ & $0,00 \mathrm{~b}$ & $72,17 \mathrm{~b}$ \\
\hline Nativo $^{\circledR}$ & $0,00 \mathrm{c}$ & $0,00 \mathrm{~b}$ & $0,00 \mathrm{c}$ \\
\hline Gauss $^{\circledR}$ & $0,00 \mathrm{c}$ & $0,00 \mathrm{~b}$ & $0,00 \mathrm{c}$ \\
\hline Priori Xtra ${ }^{\circledR}$ & $0,00 \mathrm{c}$ & $0,00 \mathrm{~b}$ & $0,00 \mathrm{c}$ \\
\hline $\mathrm{CV}(\%)$ & 9,80 & 20,61 & 8,79 \\
\hline
\end{tabular}

Médias seguidas pela mesma letra, na coluna, não diferem significativamente entre si pelo teste de Scott-Knott ao nível de 5\% de probabilidade.

* Para análise dados transformados em $(\mathrm{x}+1)^{0,5}$

** Para análise de dados transformados em arsen $(\mathrm{x} / 100)^{0,5}$

Fonte: Autores (2021).

O isolado UFMS 06 na presença do fungicida Aproach Prima ${ }^{\circledR}$ teve um pequeno crescimento vegetativo, sendo estatisticamente diferente da testemunha, os demais fungicidas afetaram o crescimento vegetativo e a produção de conídios (Tabela 2). 
Todos os fungicidas interferiram na germinação dos conídios do isolado UFMS 06, exceto Domark ${ }^{\circledR}$ (Tabela 2). Para o isolado UFMS 07 o fungicida Domark ${ }^{\circledR}$ não teve interferência na germinação dos conídios, sendo estatisticamente diferente. Os demais fungicidas inibiram a germinação dos conídios (Tabela 2). Loureiro et al. (2002) testaram nove fungicidas sobre os fungos entomopatogênicos B. bassiana, M. anisopliae, Isaria fumosorosea (=Paecilomyces fumosoroseus) e Lecanicillium lecanii e verificaram maior interferência sobre o crescimento vegetativo e conidiogênese Tebuconazole (Folicur $200 \mathrm{CE}^{\circledR}$ ) e Tetraconazole (Domark $\left.100 \mathrm{CE}^{\circledR}\right)$.

Segundo Sosa-Gomez (2005) avaliando o crescimento e germinação do fungo M. rileyi na presença dos fungicidas Tebuconazole (Folicur $200 \mathrm{CE}^{\circledR}$ ), Epoxiconazole + Pyraclostrobin $\left(\right.$ Opera $\left.^{\circledR}\right)$ Tetraconazole (Domark $100 \mathrm{CE}^{\circledR}$ ), Azoxytrobin $\left(\right.$ Prior $\left.^{\circledR}\right)$, Difenoconazole $\left(\right.$ Score $^{\circledR}$ ) Propiconazole $\left(\right.$ Tilt $\left.^{\circledR}\right)$, Trifloxystroin + Ciproconazole (Sphere ${ }^{\circledR}$ ), Flutriafol $\left(\right.$ Impact $^{\circledR}$ ) e Ciproconazole + Propiconazole $\left(\right.$ Artea $\left.^{\circledR}\right)$ concluiu que todos os fungicidas afetaram o desenvolvimento do fungo. Wenzel et al. (2008) avaliando os fungicidas Tebuconazole (Folicur $200 \mathrm{CE}^{\circledR}$ ), e Propiconazole + trifloxistrobina (Stratego $250 \mathrm{EC}^{\circledR}$ ) afetaram o crescimento vegetativo e a esporulação do fungo $L$. lecanii.

Segundo Juliatti (2005) os triazóis atuam na formação do ergosterol, que é um importante lipídio fúngico para a formação da membrana das células. A ausência desta camada leva ao colapso à célula fúngica (micélio) e a interrupção do crescimento micelial (corpo fúngico).

As estrobilurinas atuam na forma inespecífica nas membranas dos fungos, inibindo a ação proteica e enzimática (Ghini; Kimati, 2000). Fato esse que pode ter ocorrido neste trabalho por não apresentarem crescimento vegetativo e nem a produção de conídios dos dois isolados do fungo M. rileyi.

Segundo Alves; Lopes (2008) está elevada viabilidade dos conídios produzidos na presença de alguns produtos pode ter ocorrido devido a degradação e metabolização dos princípios tóxicos das moléculas químicas pelo fungo.

\subsection{Classificação dos fungicidas utilizados quanto ao índice biológico}

Todos os produtos testados aos isolados UFMS 06 e 07 de M. rileyi foram classificados como tóxicos (Tabela 3). Os fungicidas Domark $^{\circledR}$ e Aproach Prima ${ }^{\circledR}$ apresentaram valores de índice biológico de 0 a 41 sendo considerados tóxicos ao fungo M. rileyi. Estudos realizados por Pessoa; Loureiro (2013) avaliando-se o efeito dos fungicidas Aprouch Prima ${ }^{\circledR}, \mathrm{Nativo}^{\circledR}$, Priori $^{\circledR}$, Priori Xtra ${ }^{\circledR}$, Fox $^{\circledR}$ e Opera $^{\circledR}$ (Estrobilurinas + Triazol e/ou carboxamida), recomendados para o controle da ferrugem da soja, nas doses mínima e máxima, sobre o fungo M. rileyi (isolado UFMS 02), verificaram que todos os fungicidas e doses testados reduziram significativamente o crescimento vegetativo, a viabilidade dos conídios e o número de unidades formadoras de colônia do fungo, sendo todos considerados tóxicos e incompatíveis.

Essa incompatibilidade possivelmente está relacionada à composição destes fungicidas, pois os produtos fitossanitários contêm ingrediente ativo (ia) e um percentual de inertes, substâncias nas quais potencializam a ação destes produtos e muitos destes, podem ser tóxicos aos microrganismos (Conceschi, 2017). 
Tabela 3. Valores de Índice Biológico e Classificação para os isolados UFMS 06 e 07 de M. rileyi.

\begin{tabular}{|c|c|c|c|c|}
\hline \multirow[b]{2}{*}{ Tratamento } & \multicolumn{2}{|c|}{ Índice biológico } & \multicolumn{2}{|c|}{ Classificação } \\
\hline & UFMS 06 & UFMS 07 & UFMS 06 & UFMS 07 \\
\hline Testemunha & \multicolumn{2}{|c|}{ - } & \multicolumn{2}{|c|}{ - } \\
\hline Aproach Prima $^{\circledR}$ & 6,32 & 7,46 & TÓXICO & TÓXICO \\
\hline Domark $^{\circledR}$ & 8,22 & 8,85 & TÓXICO & TÓXICO \\
\hline Nativo $^{\circledR}$ & 0,00 & 0,00 & TÓXICO & TÓXICO \\
\hline Gauss $^{\circledR}$ & 0,00 & 0,00 & TÓXICO & TÓXICO \\
\hline Priori Xtra ${ }^{\circledR}$ & 0,00 & 0,00 & TÓXICO & TÓXICO \\
\hline
\end{tabular}

Fonte: Autores (2021).

\section{Conclusão}

Todos os fungicidas utilizados inibiram o crescimento micelial, concentração e germinação dos conídios nas doses utilizadas para os isolados do fungo M. rileyi.

No teste de índice biológico todos os fungicidas testados foram classificados como tóxicos para os isolados do fungo M. rileyi.

Sugere-se que seja realizado novos estudos utilizando diferentes fungicidas, concentrações e isolados são necessários para elucidar o potencial deste agente, aumentando a eficiência de controle em menor tempo, para se propor um programa de controle microbiano desta espécie-praga.

\section{Agradecimentos}

A Coordenação de Aperfeiçoamento de Pessoal do Nível Superior (CAPES) pela concessão da bolsa de estudo. Este estudo foi financiado em parte pela Coordenação de Aperfeiçoamento de Pessoal de Nível Superior - Brasil (CAPES), Código de Financiamento 001, e pelo Conselho Nacional de Desenvolvimento Científico e Tecnológico (CNPq), Código de Financiamento 001; Universidade Federal de Mato Grosso do Sul (UFMS), pelos recursos para publicar este manuscrito. Aos membros do grupo de pesquisa LAMIP.

\section{Referências}

Alves, S. B., \& Lopes, R. B. (2008). Controle microbiano de pragas na América Latina: Avanços e desafios (Vol. 14). FEALQ.

Barbosa Junior, G. B. (2020). 37p. Viabilidade no uso de fungos entomopatogênicos no sistema de cultivo de soja. $2020.37 f$. Dissertação (Mestrado)-Curso de Pós-Graduação em Agronomia, Chapadão do Sul

Boiça Junior, B., Leal, A., Bottega, D. B., Sardinha de Souza, B. H., Lobato Rodrigues, N. E., \& Michelin, V. (2015). Determinação dos tipos de resistência a Spodoptera cosmioides (Walker) (Lepidoptera: Noctuidae) em genótipos de soja. Semina-ciencias Agrarias, $607-618$.

Bueno, A. de F., Carvalho, G. A., Santos, A. C. dos, Sosa-Gómez, D. R., \& Silva, D. M. da. (2017). Pesticide selectivity to natural enemies: Challenges and constraints for research and field recommendation. Ciência Rural, 47(6).

Conceschi, M. R. (2017). Parâmetros a serem considerados nas pulverizações do fungo Isaria fumosorosea para o manejo de Diaphorina citri. Universidade de São Paulo.

Dias, P. M., de Souza Loureiro, E., Amorim Pessoa, L. G., Mendes de Oliveira Neto, F., de Souza Tosta, R. A., \& Teodoro, P. E. (2019). Interactions between fungal-infected Helicoverpa armigera and the predator Chrysoperla externa. Insects, 10(10), 309.

Ghini, R., \& Kimati, H. (2000). Resistência de fungos a fungicidas. Jaguariúna: Embrapa Meio Ambiente, 2000.

Juliatti, F. C. (2005). Modo de ação dos fungicidas sobre plantas e fungos. Simpósio sobre Relação entre Nutrição Mineral e Incidência de Doença de Plantas [Internet].

http://www.potafos.org/ppiweb/pbrazil.nsf/926048f0196c9d4285256983005c64de/4d4c7e5503f5a2c503256fdd004c4a8f/\$FILE/Anais\%20Fernando\%20Juliat ti.pdf 
Khun, K. K., Ash, G. J., Stevens, M. M., Huwer, R. K., \& Wilson, B. A. (2021). Compatibility of Metarhizium anisopliae and Beauveria bassiana with insecticides and fungicides used in macadamia production in Australia. Pest Management Science, 77(2), 709-718.

Lopes, R. B., Souza, D. A., Rocha, L. F., Montalva, C., Luz, C., Humber, R. A., \& Faria, M. (2018). Metarhizium alvesii sp. Nov.: A new member of the Metarhizium anisopliae species complex. Journal of invertebrate pathology, 151, 165-168.

Loureiro, E. de S., de Souza Tosta, R. A., Dias, P. M., Pessoa, L. G. A., de Oliveira Neto, F. M., Devoz, G. L. R., \& Muchalak, F. (2020). Performance of Metarhizium rileyi applied on Helicoverpa armigera (Hubner) (Lepidoptera: Noctuidae). Journal of Neotropical Agriculture, 7(1), 60-65.

Loureiro, E. de S., Moino JR, A., Arnosti, A., \& Souza, G. C. (2002). Efeito de produtos fitossanitários químicos utilizados em alface e crisântemo sobre fungos entomopatogênicos. Neotropical Entomology, 31(2), 263-269.

Pereira, A. S., Shitsuka, D. M., Parreira, F. J., \& Shitsuka, R. (2018). Metodologia da pesquisa científica.[e-book]. Santa Maria. Ed. UAB/NTE/UFSM. Disponível em: https://repositorio. ufsm. br/bitstream/handle

Pessoa, L. G. A., \& Loureiro, E. de S. (2013). Compatibilidade de fungicidas utilizados no controle da ferrugem asiática (Phakopsora pachyrhizi) (Sydow; P. Sydow) (Basidiomicotina: Urediniomycetes) com o fungo entomopatogênico Nomuraea rileyi (Farlow) Samson (Deuteromycotina: Hyphomycetes). $13^{\circ}$ Simpósio de controle biológico, Bonito, MS

Pessoa, L. G. A., Souza, T. M. N., \& de Souza Loureiro, E. (2020). Compatibilidade de inseticidas utilizados no manejo de pragas em eucalipto com Beauveria bassiana (Cordycipitaceae). Research, Society and Development, 9(8), e322985148.

Reddy, D. S., Reddy, M., \& Pushpalatha, M. (2018). Interaction of fungicides with bio-control agents. J Entomol Zool Stud., 3, $2098-2104$.

Rossi-Zalaf, L. S., Alves, S. B., Lopes, R. B., Silveira Neto, S., \& Tanzini, M. R. (2008). Interação de microrganismos com outros agentes de controle de pragas e doenças. Controle microbiano de pragas na América Latina: avanços e desafios, 270-302.

Silva, R. Z. da, Neves, P. M. de O. J., \& Santoro, P. H. (2005). Técnicas e parâmetros utilizados nos estudos de compatibilidade entre fungos entomopatogênicos e produtos fitossanitários. Semina Ciênias Agrárias, 26(3), 305-312.

Sosa-Gomez, D. R. (2005). Seletividade de agroquímicos para fungos entomopatogênicos. Embrapa Soja-Outras publicações científicas (ALICE). https://www.alice.cnptia.embrapa.br/bitstream/doc/444633/1/seletivfung.pdf

Sujii, E. R., Tigano, M. S., \& Sosa-Gomes, D. (2002). Simulação do impacto do fungo Nomuraea rileyi em populações da lagarta da soja, Anticarsia gemmatalis. Pesquisa Agropecuária Brasileira, 37(11), 1551-1558. 